\title{
A Web-Based Student Support Services System Integrating Short Message Service Application Programming Interface
}

\author{
Maria Concepcion S. Vera and Benilda Eleonor V. Comendador
}

\begin{abstract}
This paper presents the integration of Short Message Service Application Programming Interface in a Web-Based Student Support Services System for a university would facilitate two-way communication between the students, faculty and other stakeholders. It aims to keep in contact with students and deliver significant information arising from the University using the system's SMS facility offering auto-reply feature. Based on the survey, the respondents highly accepted the developed system. Thus, utilizing it as an alternative to the university's existing media of communication would enable the system users to avail of an effective and convenient manner of getting information from the university anytime. The manner of disseminating would become speedy, timely, and appropriate. Furthermore, using the system in an academe would result to paperless capturing, speedy recording and filing of students' records; standardized format of academic-related forms, timely dissemination and receipt of academic-related information through SMS; and production of accurate reports.
\end{abstract}

Index Terms-Web-based student support services system, student support services, short message service, application programming interface, SMS-API.

\section{INTRODUCTION}

ICT comprises any devices that are used to communicate allowing the transmission of information to an individual or group of individuals anywhere, geographically. Such devices includes radio, television, cellular phones, computer and network hardware and software, satellite systems and even videoconferencing and distance learning [1]. In education, ICT has the ability to make change possible that at some point or another may touch teaching methodologies and strategies and the student's approaches to learning as well [2]. And through ICT, information, ideas and experiences from an array of diverse people, societies and beliefs can be accessed so easily and rapidly [3]. As stressed by Danner and Pessu, education is the paramount key area for ICT [4]; and it helps improve students' learning by using modern ICTs in the form of wireless networks, internet, search engines, databases and websites [3].

Yet, most universities do not use ICT, such as Short Message Service (SMS), to obtain up-to-date information about students, particularly personal records and grades,

Manuscript received March 1, 2016; revised April 12, 2016. This work was supported in part by the Polytechnic University of the Philippines.

M. C. S. Vera is with Polytechnic University of the Philippines. She is also with Catanduanes State Universit, Philippines (e-mail: suarec@yahoo.com).

B. E. V. Comendador is with Polytechnic University of the Philippines, Philippines (e-mail: bennycomendador@yahoo.com). university-related events and activities, announcements and notice of meetings. By-request services that provide prompt delivery of pertinent records are hard to come by. Grade report cards that notify the students and faculty about computed grades are not stored electronically. Consequently, receipt of academic information on a timely basis could not be guaranteed. Observable delays in transmitting and receiving information, even losses of valuable information, take place now and then. Clearly, the primary cause is the method of disseminating information in use, like bulletin boards, memorandums for notice of meetings and other related information, or verbal communication.

Indeed, communication plays a vital role in all universities. It is crucial in their operation, not only in the pursuit of academic excellence, but also in the on-time delivery of quality services to its intended clientele. Evidently, the need is to adopt innovative ways in dealing with student needs through integration of SMS and the Web.

In response to the urgency of enhancing the IT needs of students and other stakeholders, the issues raised related to information dissemination, the need to develop a system is recognized. One that seeks to adopt the use of electronic methods of communication to keep in constant contact with students and to deliver significant information relative to or arising from the University.

The system uses SMS in disseminating information where SMS messages are sent from mobile device and/or from the web-based interface of the system via Hypertext Transfer Protocol (HTTP) to the short code provided by the SMS Application Programming Interface (API) integrated on the system. This facilitates two-way communication between the students and the university. With the system's web-based user interface, student's grades are stored and reports are speedily generated for decision-making purposes, whereby all information are stored and retrieved from a centralized database.

Short Message Service (SMS) is a text messaging facility of mobile communication systems that send short messages thru mobile networks. It uses standardized communications protocols to allow mobile phone devices to exchange short text messages not more than 160 characters [5]. API is a software-to-software interaction requesting the other program to provide service which permits access to data or somewhat perform a function [6]. It can easily be integrated with any web-based application. Once SMS API is integrated on the application system, it enables the users to send, receive and reply SMS using mobile numbers or short SMS codes through an HTTP POST interface and it seamlessly connect 
applications to the major carriers, particularly in the Philippines, without any hassle [7].

The use of cellular phones, through SMS messaging, is still the best, fastest, and most effective way to communicate. Communication carried on via a mobile phone has become popular among students when SMS was introduced.

According to a report entitled "Philippines - Mobile Communications, Forecasts and Broadcasting Market", the number of mobile telephone subscribers had grown to approximately 113 million during the early quarter of $\mathrm{CY}$ 2015 , with mobile penetration moving past $114 \%$ in this country of almost 100 million people. In the Philippines, around two billion SMS messages were being sent every day that it remains to generate the largest SMS volume in the world [8]. In Catanduanes, mobile telephone subscribers most likely increased for the past decade due to the absence of land line telephone systems.

Kajumbula mentioned in his study that in the developing world, communication in universities and colleges through SMS not only now exists but has been existing [9]. In particular, the Philippines with its large and small islands having colleges and universities, students prefer the use of SMS as the primary means of communicating with faculty and other students comparable to the findings of Nonyongo et al. that UNISA students find communication through SMS to be efficient and convenient [10].

From this perspective, the focus of this study was to develop a web-based system that integrates SMS API for student support services that facilitates two-way communication between the students and the university.

\section{CONCEPTUAL FRAMEWORK}

Fig. 1 presents the over-all conceptual framework based on the Input-Process-Output (IPO) system. This system is composed of interrelated elements that served as guide in pursuing the problem under investigation.

The first box is referred to as the input. This box includes the requirements needed before the study can be investigated such as information and knowledge requirements which are the profile of the students, faculty and employees, students' grades, class list, student's inquiry on grades and other records/announcements via SMS, SMS messages to students, faculty and employees, university announcements, activities and events and the respondent's responses on the survey questionnaires distributed; software and hardware requirements for the development of the system. The information on these variables is essential in the fulfilment of the objectives of this study.

The second box is called the process. Specifically, it contains all the procedures taken in this study such as verifying the system requirements, designing the database and graphical user interface (GUI), development of the system's prototype, data conversion, testing and debugging the system, conducted assessment survey, tabulated and analyzed the respondent's responses based on the survey questionnaires distributed.

The third box is the expected output. It offers the findings of the study based on the evaluation of the respondents on how the system is acceptable to them and the recommendations to improve/enhance the system were formulated to address the needs of the university.

The output of this study, the developed system, had been subjected to feedback from the students enrolled in the university and the faculty and staff of the university. Their feedbacks served as input to the implementation/enhancement of the developed system.

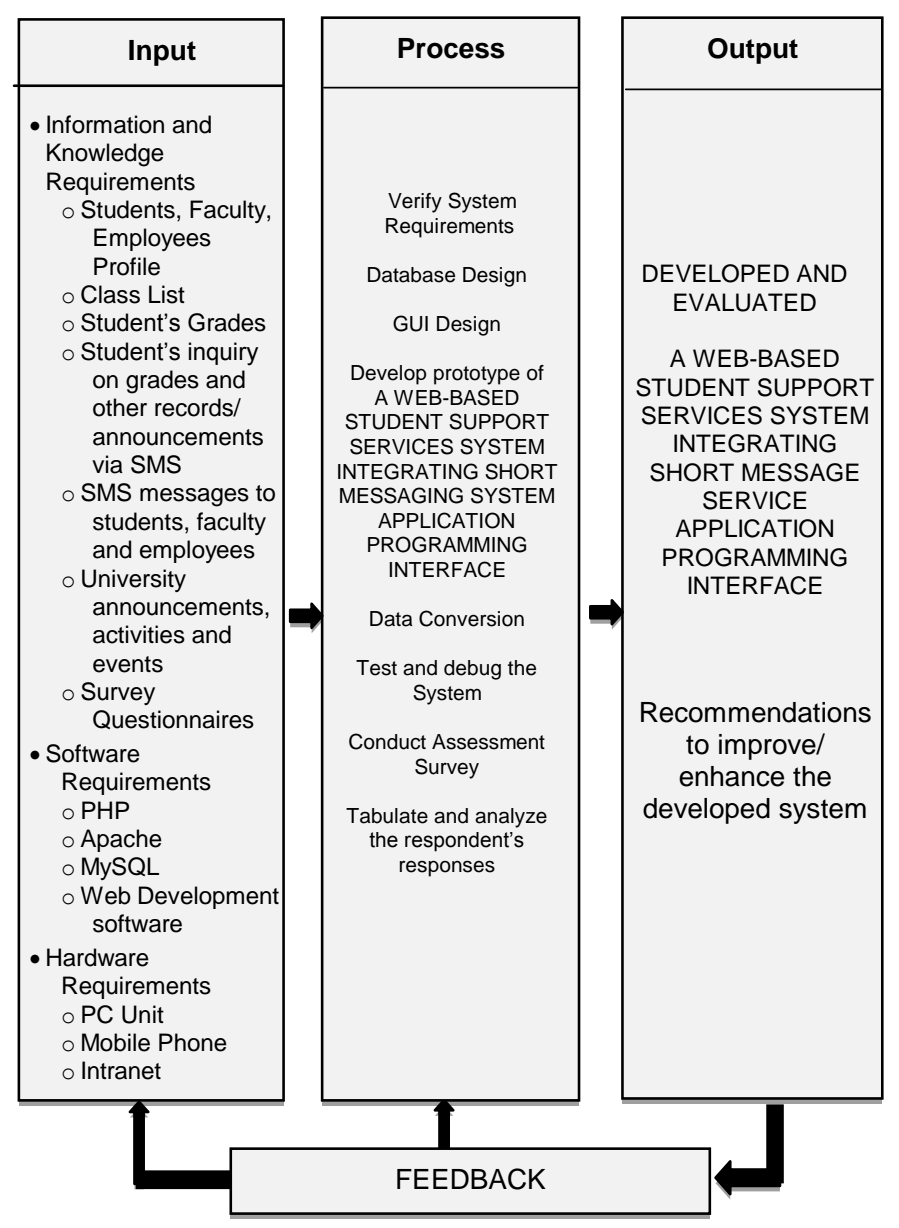

Fig. 1. Conceptual model of the study using IPO.

\section{METhODOLOGY}

\section{A. Baseline Study}

The study utilized the descriptive and developmental method of research. The descriptive research employed documentary analysis and administration of survey using a structured questionnaire. Whereas, the developmental research method was used to build the system. The respondents of the study, who were taken from the Catanduanes State University, were identified using stratified random sampling method.

The instrument used in this study is a survey questionnaire distributed to the respondents. The questionnaire consists of four parts. In part one, the respondents were asked to rate the effectiveness of the university's existing communication mechanism. In part two, the respondents were asked to determine the level of agreement on the existing university's communication mechanism in terms of speed, timeliness and appropriateness. In part three, the respondents were asked on their profile in terms of mobile usage and connectivity. Lastly, 
in part four, the respondents were asked to determine the level of acceptance on the developed system in terms of functionality, efficiency, reliability, usability, maintainability and portability were the criteria was based on ISO9126-1 software quality model [11].

To get the perception of the respondents on the developed system, the Likert Scale was used. Table I shows the criteria used to quantify the respondents' responses to the questions indicated on the survey questionnaire.

\begin{tabular}{ll} 
& TABLE I: RATING SCALE CRITERIA \\
\hline \hline Rating Scale & Verbal Interpretation \\
\hline $4.3-5.0$ & Very Highly Acceptable \\
$3.5-4.2$ & Highly Acceptable \\
$2.7-3.4$ & Moderately Acceptable \\
$1.9-2.6$ & Slightly Acceptable \\
$1.0-1.8$ & Not Acceptable \\
\hline \hline
\end{tabular}

To test the effectiveness of the developed software, a pilot test was done at the Catanduanes State University. There were one hundred sixty-six (166) participants which includes students, faculty, college dean and college clerk from the College of Information and Communications Technology and staff of the university who are directly impacted by the communication mechanisms popularly utilized within the university.

\section{B. Software Development}

Rapid Application Development (RAD) system prototyping methodology was chosen to develop the system because it requires minimum planning for rapid prototyping [12].

RAD was conducted using the system prototyping methodology. The development of the system prototype begins after the analysis, design and implementation phases has been concurrently performed. The developed prototype is used by the end-users and they give feedback and evaluation. Following user's feedback, the system is reanalyzed, redesigned and reimplement another version of the prototype. This cycle stops when the end-users and developers agree that the prototype is fully functional and ready for installation. Fig. 2 shows the system prototyping methodology process [13].

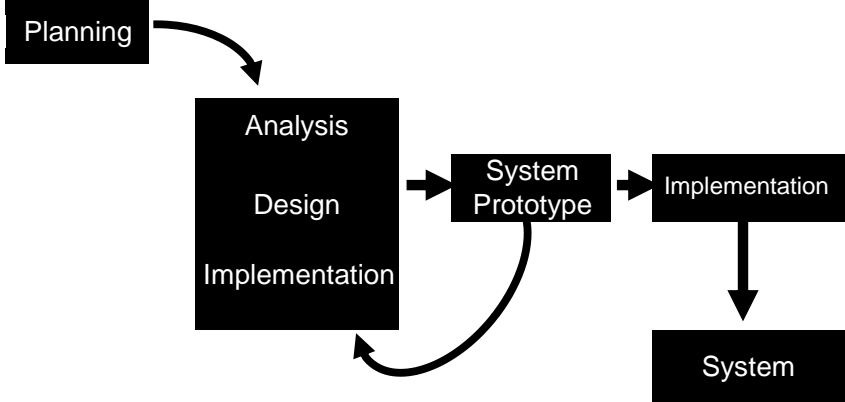

Fig. 2. System prototyping methodology process.

In addition, data flow diagram was used to show the flow of data through the various processes of the developed system and the Hierarchical Input Process Output (HIPO) model to represent the modules of a system as a hierarchy and to document each module [14].

The system was built using open-source tools - Apache, Hypertext Preprocessor (PHP), and MySQL.

\section{System Architecture}

The developed system is a 3-tier application that comprises the graphical user interface on the client, business logic and the database on the server.

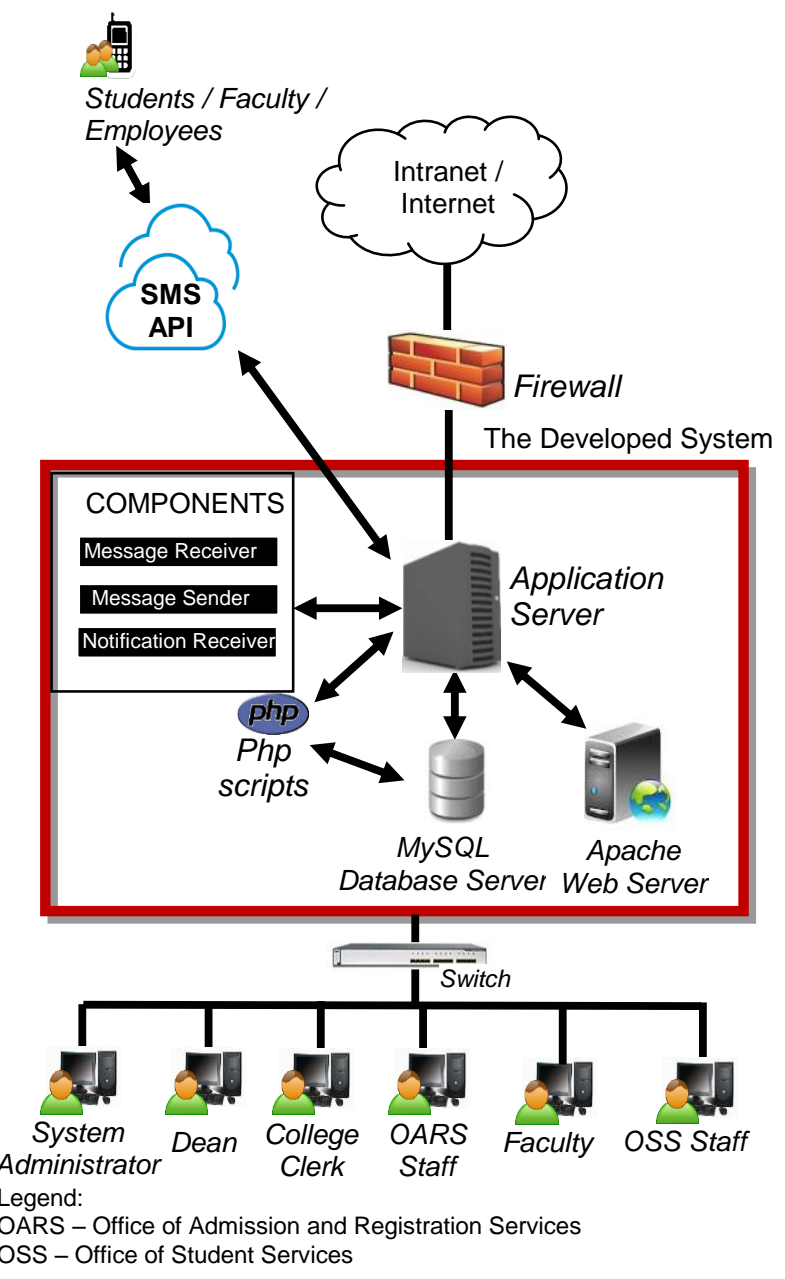

Fig. 3. System architecture.

Fig. 3 depicts the system architecture of the developed system based on the university's local area network (LAN) setup. It utilizes transmission control protocol/Internet protocol over the Intranet, network available only to the members of the organization, or even on the Internet. The box at the middle signifies the boundaries of the developed system and the SMS API positioned outside the box connects to the developed system handles the sending and receiving of SMS using the SMS short codes provided by the system.

The components of the developed system include: (a) SMS API Components. The message receiver, message sender and notification receiver are the three components included on the system's libraries to be able to use the SMS API services. To be able to receive and reply to an SMS, the user sends an SMS to an SMS API access code and the message receiver component of the system receives the SMS from the SMS API and it replies and sends it back to the SMS API. It is the SMS API that delivers the reply message to the user and the notification receiver component receives the delivery notification from the SMS API; (b) Application Server. A server in the university's LAN setup that hosts and deliver the application which allows the users in a network to run the system. But, only authorized users has access to the system. 
The system consists of seven modules namely: 1) System Administrator Module; 2) College Dean Module; 3) Faculty Module; 4) College Clerk Module; 5) Admission and Registration Staff (OARS) Module; 6) Student Services Staff (OSS) Module; and 7) Students Module. All modules are interrelated that it uses the data stored in the database such as basic information of students, faculty and staff including their primary mobile number and their class schedules per semester and school year; university's calendar of activities and events with appropriate SMS codes; and the student's grades encoded by the faculty per semester and school year where the final grades are computed by the system. Once mobile numbers are stored in the database, the users of the system can send SMS using SMS codes through their mobile phone and even through the system's web user interface to inquire and to message the faculty, dean, or staff on any academic-related information such as grades obtained, university's calendar of activities and events and the users can automatically receive a reply or notification on every SMS sent. Also, reports are generated by the users of the system; (c) MySQL Database Server. It provides data storage engine, accepts connections from the PHP and perform data manipulation queries such as inserting, modifying, and retrieving data to and from the database based on the PHP server-side scripts embedded on the application. The database is mapped in the system's application server; (d) Web Server. Apache web server provides the web service that listens to the requests originating from the web browsers and serves up web-based application to the web browsers.

\section{SYSTEM FEATURES}

The features of the developed system are: login facility, session checking, account type categorization, sending and receiving of SMS messages from students, faculty and staff supporting single, bulk and broadcasting SMS, auto-reply feature for specific SMS keyword requests, student and employees profile management, encoding and submission of grade, monitoring of grades submission, monitoring of students' grades, bulk import of student and employees data from comma-separated value (CSV) formatted file and reports generation.

The reports generation includes faculty gradesheets, masterlist of students enrolled, attendance sheet per class, summary of student's grades, certification of grades, list of students with incomplete grades, failing grades and those who dropped from the course, and list of submitted and not yet submitted gradesheets.

The system has seven (7) types of users. It consists of the (1) System Administrator; (2) the college dean; (3) the faculty members; (4) the college clerk; (5) the OARS staff; (6) the OSS staff; and (7) the students.

The system administrator is the super user of the developed system. He restricts the privileges of the system users and maintains system logs.

The college dean can view and print college-related information and reports and he can send and receive academic-related SMS to students, faculty and staff.

The faculty member can view their class schedule, class list and add grades of the students for the present semester. They can print and submit semestral reports such as masterlist, attendance sheets and gradesheets for all the subjects handled in the current semester. He can also search and view student's profile and scholastic rating. Lastly, the faculty members could also send academic related SMS messages to the students through the system.

The college clerk would enable college clerks to add, update, search and view profile of the students and faculty members, view academic reports generated by the system and send academic-related SMS to the students and faculty members.

The OSS staff can view student's profile and send student activities related notices and academic-related SMS to students, manage the SMS codes for the university's calendar of activities and events.

The OARS staff can add, update and search student's profile and view student's grades, gradesheets submitted and not yet submitted, generate reports and send academic-related SMS to students.

The students can utilize only the SMS facility of the developed system using their own mobile phone. By using the SMS code, they can inquire and receive university's calendar of activities and events; grades obtained per school year and semester; list of SMS codes; and be able to send messages to faculty regarding their performance in the class and any academic-related information they need to know. Provided, however, that the primary mobile number of the students, faculty and staff are stored in the database.

\section{PROTOTYPE DEVELOPMENT}

The prototype has been developed as a web-based system integrating the SMS-API using open-source technologies. The application uses a MySQL database as backend, PHP as front-end and apache as the web server. Fig. 4 shows the home page after a user login.

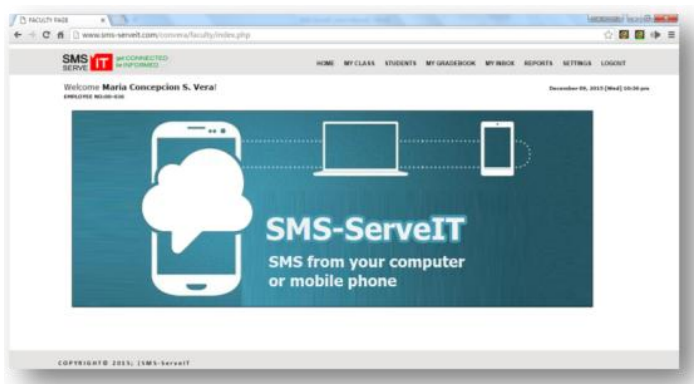

Fig. 4. The home page after logon.

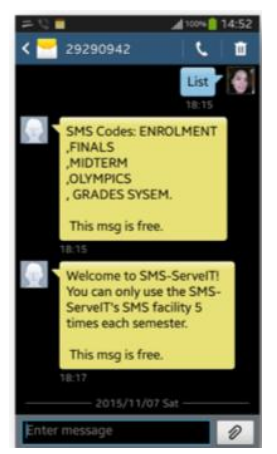

Fig. 5. To get the list of SMS codes using the syntax, <LIST> and send it to 29290942 
Students. Faculty and staff uses the SMS facility to send/receive important information arising to and from the university. The figures from Fig. 5 to Fig. 11 shows the prototype of sending and receiving SMS messages to the students and faculty/staff of the university.

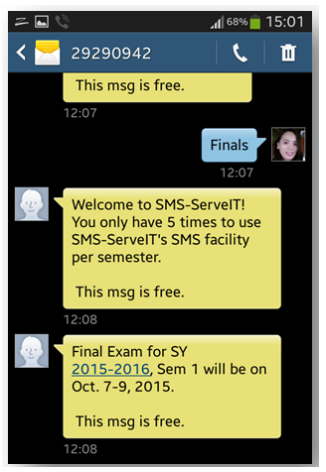

Fig. 6. SMS code to use, text <FINALS> to 29290942.

With the auto-reply feature of the system, the SMS API delivers the message to the user. From Fig. 7, the SMS message delivered to the user is the schedule of the Final Exam in the university.

Students can inquire any academic-related information to the faculty by sending the code to 29290942 from Fig. 7 and Fig. 8. The syntax is:

MSG $<$ College $><$ LastName $>$, $<$ FirstNameInitial $><$ MiddleInitial $>$ $<$ Message $>$
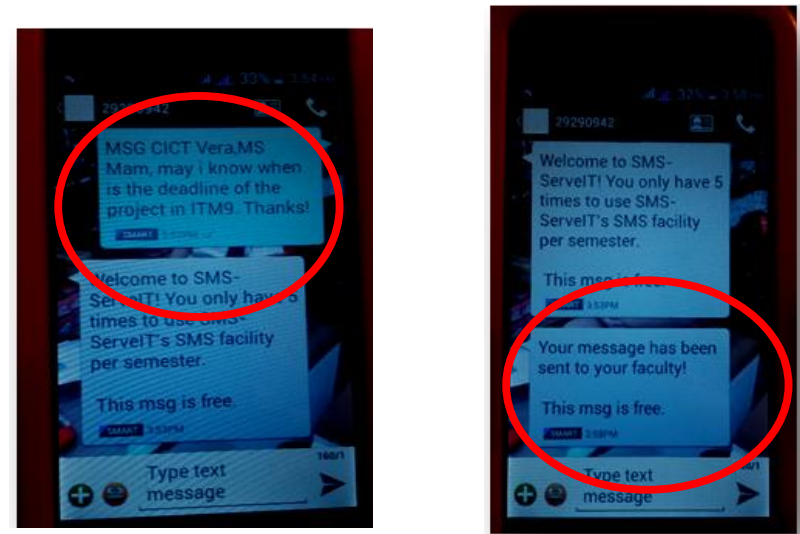

Fig. 7. Student's SMS message to faculty. Fig. 8. SMS notification to student.

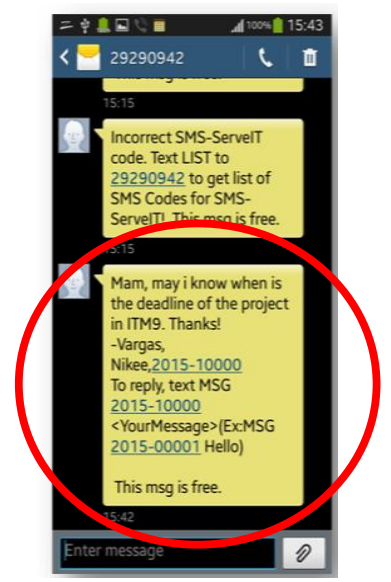

Fig. 9. Student's SMS message received by faculty.

Faculty can send SMS message to the students by sending the code to 29290942 from Fig. 10 and Fig. 11. The syntax is:
MSG <StudentNo > <Message $>$
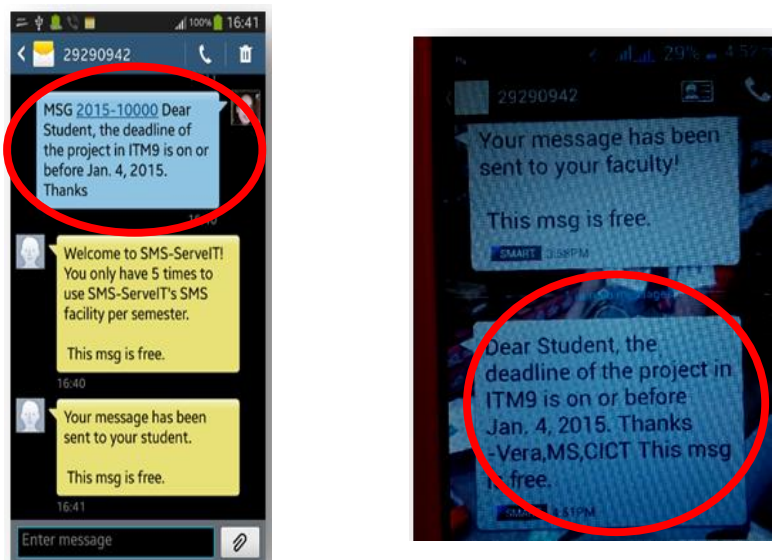

Fig. 10. Faculty SMS message to student. Fig. 11. Faculty's SMS message received by the student.

\section{RESULTS AND DISCUSSION}

Recognizing the need for a functional and effective communication mechanism for university use, grounded on innovation theories, is the raison d'être in the development of the system. The study was conducted to evaluate the level of acceptance of the developed system in terms of functionality, efficiency, reliability, usability, maintainability, and portability.

TABLE II: RESPONDENT’S LEVEL OF ACCEPTANCE OF THE DEVELOPED SYSTEM

\begin{tabular}{|c|c|c|c|c|c|}
\hline \multirow{2}{*}{ Criteria } & \multicolumn{3}{|c|}{$\begin{array}{c}\text { Average Level of } \\
\text { Acceptance (ALA) }\end{array}$} & \multirow{2}{*}{ Interpretation } & \multirow{2}{*}{ Rank } \\
\hline & Student & $\begin{array}{l}\text { Faculty } \\
\& \text { Staff }\end{array}$ & Over-all & & \\
\hline Functionality & 4.85 & 4.75 & 4.77 & $\begin{array}{l}\text { Very Highly } \\
\text { Acceptable }\end{array}$ & 6 \\
\hline Efficiency & 4.84 & 4.79 & 4.83 & $\begin{array}{l}\text { Very Highly } \\
\text { Acceptable }\end{array}$ & 5 \\
\hline Reliability & 4.85 & 4.74 & 4.84 & $\begin{array}{l}\text { Very Highly } \\
\text { Acceptable }\end{array}$ & 4 \\
\hline Usability & 4.88 & 4.77 & 4.87 & $\begin{array}{l}\text { Very Highly } \\
\text { Acceptable }\end{array}$ & 3 \\
\hline Maintainability & 4.89 & 4.80 & 4.89 & $\begin{array}{l}\text { Very Highly } \\
\text { Acceptable }\end{array}$ & 2 \\
\hline Portability & 4.93 & 4.86 & 4.93 & $\begin{array}{l}\text { Very Highly } \\
\text { Acceptable }\end{array}$ & 1 \\
\hline Overall & 4.86 & 4.77 & 4.84 & $\begin{array}{l}\text { Very Highly } \\
\text { Acceptable }\end{array}$ & \\
\hline
\end{tabular}

Table II illustrates the summary of the respondents' level of acceptance on the developed system. It can be observed from the table that in terms of "Portability" the respondents said that the system is 'Very Highly Acceptable' which ranked first and obtained the overall response of 4.93. It is followed in the second rank by "Maintainability" with an overall response of 4.89 verbally interpreted as "Very Highly Acceptable'. The third in the rank is "Usability" with an overall response of 4.87 interpreted as "Very Highly Acceptable'. "Reliability" received the fourth rank with an overall response of 4.84, which is interpreted as "Very Highly Acceptable'. The fifth in the rank is "Efficiency" with an overall response of 4.83. Lastly, "Functionality" obtained an overall response of 4.77 which is interpreted as "Very Highly Acceptable".

It can be concluded that the students, faculty and staff 
respondents considered the developed system 'Very Highly Acceptable' as revealed by the overall rating of 4.84 .

\section{RECOMMENDATIONS AND FUTURE WORKS}

Based on the evaluation made by the respondents on the existing and the developed system, the researchers arrived at the following recommendations: 1) adopt and utilize the developed system as an alternative to the university's existing media of communication such as website, printed material and public information. This would enable students and users to avail of an effective and convenient manner of getting information from the university anywhere and anytime even outside the campus; 2) employing the developed system as part of the organization manner of communication and information dissemination would mean a more speedy, more timely, and more appropriate information that would be obtained by students, faculty and other stakeholders in the university; 3 ) all the stakeholders of the university should be encouraged to acquire mobile communication devices that would support the developed system so that they could avail in full the services and benefits offered by the system, considering that minimal cost will be incurred in using the SMS Technology of the system, but benefits derived will be more than its cost. Likewise, clear cut policies on registration of mobile number, conversion/installation cost, and pricing for the SMS services should be established. Additionally, awareness campaign should be designed by the university administration in terms of technology promotion to make the students aware of the trends which would make them easily adjust to the industries during OJT or industry immersion programs; 4) for the university to achieve a full adoption rate of the system, there is a need to make a detailed utilization plan of the developed system which includes the transition plan from the existing communication process to the full adoption of developed system and for the training of the end users in utilizing the system; 5) future studies may be made on SMS-Based Enrollment System for Catanduanes State University.

\section{ACKNOWLEDGMENT}

Maria Concepcion S. Vera thanks all the people who provided expertise that greatly assisted the research and improved the manuscript significantly.

\section{REFERENCES}

[1] J. C. Omeje and E. N. Ugwuanyi, “ The use of ICT in dissemination of career information in secondary schools in Ogbadigbo local government area of Benue State Nigerua," International Institute for Science, Technology and Education, vol. 3, no. 9, pp.78-83, 2013.

[2] D. M. Watson, "Pedagogy before technology: Re-thinking the relationship between ICT and teaching," Education and Information Technology, vol. 6, no. 4, pp. 251-266, 2001.

[3] S. A. Khan, R. Bhatti, and A. Khan. (December 2011). Use of ICT by students: A survey of faculty of education at IUB. [Online]. Available: http://digitalcommons.unl.edu/cgi/viewcontent.cgi?article=1751\&con text=libphilprac

[4] R. B. Danner and C. O. A. Pessu, "A survey of ICT competencies among students in teacher preparation programmes at the University of Benin, Benin City, Nigeria," Journal of Information Technology Education, vol. 12, pp. 33-49, 2013.

[5] V. K. Katankar and V. M. Thakare, "Short message service using SMS gateway," International Journal on Computer Science and Engineering, vol. 02, no. 04, pp. 1487-1491, 2010.
[6] ComputerWorld, "Technology quick study hot treands and technologies in brief," Application Programming Interface, p. 66. January 10, 2000.

[7] Chikka API Beta. (June 18, 2015). Getting to Know the Chikka SMS API. [Online]. Available: https://api.chikka.com/help

[8] P. Budde. (August 20, 2015). Philippines - Mobile communications, forecasts and broadcasting market. [Online]. Available: http://www.budde.com.au/Research/Philippines-Mobile-Communicat ions-Forecasts-and-Broadcasting-Market.html

[9] R. Kajumbula, "The effectiveness of mobile short messaging service (SMS) technologies in the support of selected distance education students of Makerere University, Uganda," presented at the Forth Pan-Commonwealth Forum (PCF4) on Open Learning, Ochio Rios, Jamaica.

[10] E. Nonyongo, K. Mabusela, and V. Monene, "Effectiveness of SMS communication between university and students," presented at 4th World Conference on Mobile Learning, 2005.

[11] I. Fleming. (May 1, 2015). ISO 9126 software quality characteristics. [Online]. Available: http://www.sqa.net/iso9126.html

[12] R. Naz and M. N. A. Khan, "Rapid applications development techniques: A critical review," International Journal of Software Engineering and Its Applications, vol. 9, no. 11, pp. 163-176, 2015.

[13] I. A. Ajah and J. O. Ugah, "Comparative analysis of software development methodologies," International Journal of Advanced Research in Computer Science and Software Engineering, vol. 3, issue 6, pp. 655-665, June 2013

[14] OMICS International. (October 2, 2015). HIPO model. [Online]. Available:

http://research.omicsgroup.org/index.php/HIPO_model\#cite_note-2

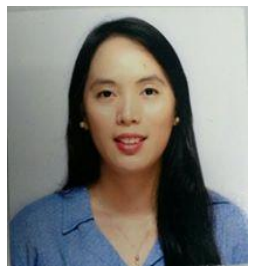

Maria Concepcion S. Vera was born in Virac, Catanduanes, Philippines on December 12, 1981 She obtained her bachelor of science in information management at the Catanduanes State University in 2002. She is in the field of academe since 2011 and currently working as instructor I at Catanduanes State University, College of Information and Communications Technology. She is a member of Philippine Society of Information Technology Educators (PSITE) Philippine Association of Researchers and Statistical Software Users (PARSSU), IAMURE Multidisciplinary Research and Philippine Schools, Universities, Colleges, Computer Education and Systems Society (PSUCCESS). Her research interests include Mobile and Wireless Network and other related Technologies, Information and Communications, Data Mining, Decision Support Systems and System Modeling.

Ms. Vera's field of specializations are fundamentals of problem-solving and programming, relational database management system (RDBMS), web development, system analysis and design, and programming languages.

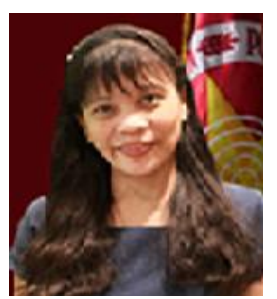

Benilda Eleonor V. Comendador is a member of Science and Engineering Institutes, Philippine Computer Society and Philippine Schools, Universities, and Colleges Computer Education and Systems Society (PSUCCESS). She was a grantee of the Japanese Grant Aid for Human Resource Development Scholarship (JDS) from April 2008 to September 2010. She obtained the master of science in global information telecommunication studies (MSGITS), major in project research at Waseda University, Tokyo Japan in 2010. She was commended for her exemplary performance in completing the said degree from JDS. She finished her master of science in information technology at Ateneo Information Technology Institute, Philippines in 2002.

Presently, she is the chief of the Open University Learning Management System (OU-LMS) and the program chair of the master of science in Information Technology (MSIT) of the Graduate School of the Polytechnic University of the Philippines (PUP). She is an associate professor and was the former chairperson of the Department of Information Technology of the College of Computer Management and Information Technology of PUP.

She attended various local and international computer related trainings and seminars. She was the country's representative to the Project Management Course in 2005, which was sponsored by the Center for International Computerization Cooperation (CICC) in Tokyo, Japan together with other 9 representatives from various ASEAN countries.

She presented several research papers in various international conferences . 